\title{
秎 \\ IDEOLOGIAS IMPORTAM - O ACESSO PARA O LOBBY EM AUDIÊNCIAS PÚBLICAS NA 55ª LEGISLATURA DA CÂMARA DOS DEPUTADOS
}

\author{
IDEOLOGIES MATTER - ACCESS FOR LOBBY IN PUBLIC HEARINGS IN THE 55th \\ LEGISLATURE OF THE CHAMBER OF DEPUTIES
}

\section{IDEOLOGÍAS IMPORTAN - ACCESO PARA LOBBY EN AUDIENCIAS PÚBLICAS EN LA $55^{\circ}$ LEGISLATURA DE LA CÁMARA DE LOS DIPUTADOS}

\author{
Luiz Paulo Vaz de Figueiredo ${ }^{1}$
}

\begin{abstract}
Resumo: Sob a perspectiva do lobby informacional, este artigo a veriguou a importância das ideologias de legisladores no acesso de grupos de interesse para a busca de influência em audiências da Câmara dos Deputados na $55^{\mathrm{a}}$ legislatura. Para isto, foram analisados requerimentos por audiências públicas feitos por deputados, do qual se extraíram dados em levantamentos sobre os perfis de convites de deputados de esquerda e direita, a distribuição de grupos de interesse por comissão, a atuação partido a partido, a dinâmica de contestação de requerimentos, entre outros. Conclui-se que as ideologias são relevantes, principalmente em padrões de convite de esquerda e direita, ainda que com algumas contradições. As audiências, em agrega do, são territórios de relativa igualda de entre esquerda e direita, ainda que audiências em específico tenham domínio ideológico. A ideologia Presidente da Comissão não altera a agenda ideológica das audiências.
\end{abstract}

Palavra-chave: Lobby; Grupos de interesse; Poder legislativo; Câmara dos Deputados; Ideologias

\begin{abstract}
From the perspective of the informational lobby, this article investigated the importance of the legislators' ideologies in the access of interest groups to the search for influence in hearings of the Cha mber of deputies in the 55th legislature. For this, requests by public hearings made by deputies were analyzed, from which data were extracted in surveys on the invitation profiles of left and right deputies, the distribution of interest groups by committee, the performance of party to party, the dynamics of dispute of requirements, among others. It is concluded that ideologies are relevant, mainly in left and right invitation patterns, although with some contradictions. Audiences, in aggregate, are territories of relative equality between left and right, even though specific audiences have an ideological domain. The President of the Commission ideology does not change the ideological agenda of the hearings.
\end{abstract}

Keywords: Lobby; Interest groups; Brazilian legislature; Chamber of deputies; Ideologies

Resumen: Desde la perspectiva del lobby informativo, este artículo indagó en la importancia de las ideologías de los legisladores en el acceso de los grupos de interés a la búsqueda de influencia en las audiencias de la Cámara de Los Diputados en la $55^{\mathrm{a}}$ legislatura. Para ello se analizaron las solicitudes de audiencias públicas rea liza das por diputados, de las cuales se extrajeron datos en encuestas sobre los perfiles de invitación de diputados de izquierda y derecha, la distribución de grupos de interés por comisión, el desempeño de partido a partido, la dinámica de disputa de requisitos, entre otros. Se concluye que las ideologías son relevantes, principalmente en patrones de invitación de izquierda y derecha, aunque con algunas contra dicciones. Las audiencias, en conjunto, son territorios de relativa igualdad entre la izquierda y la derecha, aunque audiencias específicas tienen un dominio ideológico. La ideología del presidente de la

\footnotetext{
${ }^{1}$ Mestre em Ciência Política pela Universidade Federal do Estado do Rio de Janeiro (UFRJ). E-mail: lpaulo08@hotmail.com Orcid: https://orcid.org/0000-0002-5568-8266
} 
Comisión no cambia la agenda ideológica de las audiencias.

Palabras-clave: Lobby; Grupos de interés; Poder legislativo; Cámara de los diputados; Ideologías

\section{Introdução}

Audiências públicas são espaços de caráter consultivo, onde, idealmente, a sociedade civil se faz presente para ser ouvida diante dos tomadores de decisão política. No Congresso Nacional, como parte acessória ao processolegislativo, as audiências são mantidascomo meios de obtenção de informação pelos deputados. E, pela perspectiva do lobby estratégico, dentre um universo de possibilidades, que podem englobar ações em instituições do Estado ou diretamente ao eleitorado e fazendo uso de canais de comunicação mais amplos, a presença em audiência pública é uma das táticas adotadas para que um grupo de interesse busque influenciar os que tomam decisões (SCHLOZMAN, TIERNEY, 1986; BAUMGARTNER, LEECH, 1998; WRIGHT, 1996). O uso das audiências pelos grupos de interesse tem como vantagem o baixo custo para o acesso aos legisladores (WRIGHT, 1996) e a possibilidade de aumentar a publicidade sobre o tema e atingir mais facilmente as partes interessadas na sociedade. Santos et al (2017) apontam que, no Congresso Nacional, a participação em audiências é a terceira principal ação de lobby, atrás apenas do contato direto com os parlamentares e do acompanhamento de Comissões.

O lobby no Brasil tem se profissionalizado e se intensificado, ainda que apresente suas complicações, como a desigualdade de representação provocada pelos altos custos e pelo seu lado obscuro, atribuído à falta de regulamentação no Brasil (MANCUSO; GOZETTO, 2011). Na tramitação legal, grupos de interesse se beneficiam de suas relações prévias estabelecidas com deputados. Segundo Taglialegna (2006), a atuação de grupos de interesse se dá por instituições formais e informais. Por meios formais, a atuação se dá pela "participação direta dos grupos de pressão em audiências públicas promovidas pelas Comissões do Congresso" e por meios informais, pelas "relações pessoais dos grupos de pressão com os parlamentares". .

Estudos sobre lobby anteriores que abordam audiências públicas no Legislativo ${ }^{2}$ deram sustentação especialmente ao seu aspectoinformacional (TAGLIALEGNA, 2006) e às diferenças de atuação - e maior sucesso - de certos grupos de interesse sobre outros, especialmente, dos ligados à representação do setor produtivo sobre os demais (MANCUSO, 2004; VIEIRA, 2009; MANCUSO, 2011; SANTOS, 2015; SANTOS ET AL, 2017; CESÁRIO, 2016; TROIANO, 2017). A exceção de Troiano (2017), existe uma lacuna a ser abordada, que é a importância das ideologias dos deputados no acesso destes representantes de interesses ao processo do Legislativo.

Uma série de outros trabalhos, partindo de perspectivas teóricas também abordaram audiências públicas no Legislativo. Seguindo a chave-interpretativa deliberativa, audiências

\footnotetext{
${ }^{2}$ Cabe dimensionar a extensão do uso de audiências públicas para além do Legislativo. A nível federal, há também estudos que abordam a atuação de grupos de interesse em audiências no âmbito do Executivo (SILVA, 2012; BAIRD, 2016) .
} 
públicas foram estudas, a nível local, por Brélaz(2012) eZorzal (2017)e, no Congresso Nacional, por Macedo (2018). E mais especificamente, foram estudados mais a fundo comportamentos de atores envolvidos e dinâmicas informacionais e deliberativas nas comissões de Ciência e Tecnologia, Informação e Informática (RESENDE, 2017) e Direitos Humanos (Bacovis; Santos, 2019), além de audiências públicas interativas (BARROS; MONTEIRO; SANTOS, 2018).

A análise proposta neste artigo terá como base a Teoria Informacional do Lobby, a qual defende que 'grupos de interesse atingem influência no processo legislativo estrategicamente fornecendo informação para mudar ou reforçar as crenças dos legisladores sobre os resultados legislativos, os efeitos operacionais de políticas, e as ramificações eleitorais das suas ações" (WRIGHT, 1996, p. 75). Segundo os defensores da teoria, existe um fator fundamental, que é a crença dos legisladores, a qual os grupos de interessetentammudar. No presente artigo, usaremos a ideologia (se de esquerda ou direita), a partir da escala desenvolvida por Scheefer (2017), para averiguar se a posição ideológica tem efeito sobre as escolhas dos deputados no acesso de grupos de interesse. A ideologia (se de esquerda ou de direita) se mostrou um explicativo da atuação de grupos de interesse na campanha de certos candidatos em detrimento de outros (MCKAY, 2010). E além disso, diante dos posicionamentos perante pautas de momento, ou num prazo maior, é possível estimar as ideologias dos grupos de interesse (MCKAY, 2008).

Usaremos de um banco de dados desenvolvido no período de uma legislatura do Congresso Nacional (2015-2018), extraindo dos requerimentos por audiências públicas, feitos por deputados, junto às respectivas Comissões da Câmara, dados de acesso ao processo de influência: o partido e a posição ideológica do deputado requerente, a categoria do grupo de interesse convidado, a comissão da audiência e se houve não um requerimento adicional. A partir destes dados, hipóteses serão testadas.

\section{Teoria do Lobby Informacional}

As comissões do Congresso Nacional são órgãos descentralizados, que existem idealmente para fomentar a especialização de deputados e para incentivar um debate livre sobre as matérias (ARAÚJO, 2007). As Comissões são efetivas e desempenham um "poder positivo". Em seu interior, durante os trabalhos dos seus integrantes, a maioria dos projetos de lei são alterados, com novas emendas e substitutivos antes de chegar ao Plenário da Câmara (FREITAS, 2016).

Pela perspectiva informacional, os legisladores não possuem a informação necessária sobre os efeitos das políticas, e, portanto, precisam buscá-la para a redução de incertezas. Quanto mais informação especializada obtiver o legislador médio, o Congresso mais estará consoante ao princípio organizacional. Numa organização legislativa eficiente, bens coletivos são dados ao Parlamento a partir da especialização informacional que será distribuída a todos parlamentares, principalmente àqueles com afinidade de preferência; e, em última instância, 
haverá checagem pela força decisória da maioria (KREHBIEL, 1992). Nas palavras de Santos e Almeida (2005): “A audiência pública é o mecanismo regimental mais diretamente voltado para a coleta de informação (alternativa à do governo) sobre as consequências de políticas públicas." Além das audiências, atores específicos possuem papel informacional nas comissões. A relatoria é fundamental, para além do formalismo das posições, tendo "poder de fato" sobre o conteúdo dos projetos (SANTOS; ALMEIDA, 2005); e a assessoria parlamentar é redutora de incertezas, qualificando informacionalmente as decisões tomadas (SANTOS, 2014).

Para além da análise dos atores do legislativo como agentes informacionais que se interrelacionam num "sistema fechado", os grupos de interesse podem ser apontados como atores participantes externos, trazendo informações novas, se posicionando, apresentando petições, memoriais ou pareceres aos deputados federais (ZAMPIERI, 2013).

Esta dinâmica informacional é bem descrita pela Teoria do lobby Informacional, na qual existe um relacionamento de aproximação entre grupos de interesse e legislador. O grupo de interesse, portador da informação $0^{3}$, busca o legislador, afim de influenciar a política pública em questão, conforme seu interesse; por outro lado, o legislador busca o grupo de interesse porque ele possui a informação essencial e custosa para fundamentar suas decisões e, assim, fazer melhores políticas, se destacar na carreira legislativa e garantir reeleição (AUSTEN-SMITH, 1992; LEYDEN, 1995; WRIGHT, 1996).

Para descrever temporalmente esta relação mútua, Wright (1996) elaborou um contínuo elucidativo do processo de influência pretendido pelo grupo de interesse, que a partir de divergências teóricas, nunca tinha se definido com exatidão. O autor cita diversas definições dadas para o fenômeno, sendo a de Hansen (1991) a mais popular. Para este autor, o acesso é a "relação próxima entre membros do Congresso e outsiders privilegiados" (HANSEN, 1991, p.77). Seccionando em etapas para evitar a interposição sugerida pelas teorias prévias, Wright (1996) representa no contínuo um processo que vai do acesso dos grupos de interesse aos legisladores até o momento final a ser concretizado, que é a influência efetiva da posição do grupo sobre a do legislador.

O acesso é o primeiro dos objetivos dos lobistas no legislativo e pode ser dividido em duas partes: posicionamento e mensagem. No primeiro, os lobistas estabelecem contatos com os legisladores e seus assessores, mas sem desenvolver suas pautas específicas. Na mensagem, a informação relevante é exposta sobre a legislação específica. Nesta etapa se encontram as audiências. O acesso é feito para, em última instância, alcançar mudança de crença prévia do legislador pela mensagem do lobista - a influência.

\footnotetext{
${ }^{3}$ Dahm \& Porteiro (2008) analisaram se a informação sendo entregue de maneira estratégica não resultaria em omissões de dados importantes. Os autores concluíram que a retenção é baixa, e os lobistas tendem a buscar um caminho de maior credibilidade.
} 
Figura 1 - Contínuo a cesso-influência

\begin{tabular}{|l|l|l|l|l|}
\hline & 1a.Posicionamento & 1b.Mensagem & & \\
\hline 0.Sem acesso & 2.Anfluência
\end{tabular}

Fonte: Wright (1996)

Um outro desenlace da teoria, que será neste artigo testado, são as duas possibilidades estratégicas de lobby segundo as crenças: o lobby persuasivo, que age na intenção de mudar as crenças prévias de um legislador sobre uma política e o lobby contrariante, que serve como prevenção à mudança de crença em legisladores já simpáticos à política defendida pelo grupo de interesse. As duas acontecem apenas em situações de necessidade efetiva. Em outras palavras, quando há chance de um legislador contrário mudar para a opinião favorável ou quando um legislador a favor está sofrendo lobby de outro grupo para ser contra (WRIGHT, 1996). Explorando essa discussão, Hojnacki \& Kimball (1998) afirmou que o lobby persuasivo seria feito muito particularmente em fases seminais do processo legislativo, em que o projeto tem uma imagem ainda neutra, sem posiçõesestabelecidas contrárias ou a favor. Já Hall \& Deardoff (2006) se opuseram à ideia do lobby persuasivo, defendido por Wright (1996), Austen-Smith \&Wright (1994), Hansen (1991) e outros. Para eles,

(....) o lobby direto tipicamente não é uma estra tégia para mudar as preferências dos legisladores sobre as políticas. Mas sim, é uma tentativa de subsidiar os recursos legislativos dos membros que apoiam a causa do grupo (...) (HALL; DEARDOFF, 2006,p.72).

Logo, o lobbyé mais um subsídioinformacional do que uma estratégiade persuasão capaz de virar posicionamentos de opositores. Assim, o dispêndio de recursos dos grupos de interesse é racionalizado, não procurando convencer parlamentares com baixa probabilidade de troca de opinião.

Mais tarde, Groll e Prummer (2016) reafirmaram o lobby contrariante, mas também sustentaram a tese do lobby persuasivo. Segundo o estudo, grande parte do esforço seria em tomadores de decisão indecisos ou não enviesados, assim como em tomadores de decisão já predispostos a seguirem as posições do lobista. Este resultado é consistente com o que de Figueiredo e Richter (2014) haviam notado:

(...) parece existir um consenso crescente na literatura de que ambos, aliadose legisladores marginais, nos dois lados da questão são alvos de esforços lobísticos, mas inimigos convictos não são (...) (FIGUEIREDO; RICHTER, 2014,P. 167).

Schnakenberg (2017) foi mais uma confirmaro alvo dos lobistas nos legisladores aliados, e detectou ainda um outro fenômeno, não percebido através de modelos analíticos anteriores: os grupos de interesse usam de legisladores aliados para persuadir legisladores opositores. Logo, pode existir uma transferência de uma atribuição informacional de persuasão, a priori, entendida 
como do lobista para o legislador aliado, que passaria a ter o papel de converter o voto a seu favor.

\section{Metodologia}

Em busca do entendimento do papel das ideologias no acesso de grupos de interesse para o lobby em audiências públicas, a partir dos requerimentos feitos por legisladores para sua realização, os dados usados são extraídos dos convites feitos, ou seja, que expõem as relações de legisladores de que partidos, que possuem determinada ideologia, convidam certo grupo de interesse, de determinada categoria específica. É uma forma de presumir a "relação próxima" indicada por Hansen (1991). Na audiência pública, conforme a teoria, o grupo de interesse faz a entrega do conteúdo de sua mensagem explicitamente, afim de influenciar o legislador. Cabe enfatizar que as dinâmicas da audiência em si, como as exposições dos oradores, interpelações de legisladores e conteúdos das atas não serão considerados ${ }^{4}$, apenas os convites para a audiência. A pergunta norteadora deste presente artigo então será: o acesso de grupos de interesses a audiências públicas do Congresso Nacional é determinado pelas crenças dos legisladores?

Os dados a serem analisados por este estudo são extraídos do site oficial da Câmara dos Deputados $^{5}$, respeitando o seguinte recorte: audiências públicas com a finalidade específica de tratar de mudanças na legislação ${ }^{6}$ ocorridas em Comissões permanentes da Câmara dos Deputados realizadas no período da $55^{\text {a }}$ Legislatura (de janeiro de 2015 a dezembro de 2018). Para este período, serão considerados os seguintes aspectos: 1) o partido do deputado requerente da audiência pública; 2) a categoria do grupo de interesse convidado; 3 ) o partido do presidente da Comissão no momento da audiência. O total analisado se deu entre as 25 Comissões permanentes da Câmara dos Deputados, em 205 audiências com vistas à mudança na legislação e tendo 1157 convidados.

O banco de dados construído para este artigo é limitado a somente um tipo específico de audiência pública: aquelas envolvendo mudança na legislação, ou seja, na modificação de leis ou na criação de novos ordenamentos jurídicos. Embora existam outros dois tipos de audiências públicas (de debates mais amplos ou de prestação de contas), escolhemos para a análise aquelas voltadas para mudanças na legislação. Essa opção se deve à adequação à Teoria de lobby Informacional no Legislativo, por ter uma finalidade bem delineada pelos grupos de interesse de alcançar uma mudança legal específica. Além disso, o recorte de Comissões permanentes não analisa as ocorridas em Comissões mistas e temporárias. Essa opção se deve ao fato de que essas Comissões são permanentes e, portanto, constantes na legislatura, além do caráter temático.

\footnotetext{
${ }^{4}$ É possível, através do Regimento Interno, presumir quatro fases nas audiências públicas ocorridas na Câmara: 1) iniciativa, partindo de um deputado; 2) aprovação do requerimento em reunião ordinária; 3) a ocorrência da audiência, com os convidados e deputados presentes expondo os seus pontos; 4) por último, o arquivamento.

${ }^{5}$ www.camara.leg.br

${ }^{6}$ Do regimento interno da Câmara, é possível extrair três tipos de audiências: sobre prestação de contas, temas gerais, ou discussão de legislação em específico. A escolha apenas do último tipo se dá devido a uma maior adequação à concepção tradicional de lobby, com o objetivo de influenciar política pública em específico.
} 
Devemos destacar que são 25 diferentes Comissões a serem analisadas. Elas variam em relação aos seus temas e, também, na fase que atuam no processo legislativo. Duas Comissões devem ser analisadas com um enfoque diferente, CCJC e CFT, pois todas as proposições serão nelas invariavelmente tramitadas.

Os partidos dos legisladores requerentes de audiências e/ou convidados são dados fundamentais, pois evidenciam as prováveis crenças políticas do legislador a ter iniciativa inicial de pedir a audiência e convidar os primeiros - muitas vezes os únicos - convidados. Para a $55^{\text {a }}$ Legislatura foram eleitos deputados de 28 diferentes partidos; sendo assim distribuídos, tendo o PT (70), PMDB (66); PSDB (54); PSD (37); PP (36); PR (34); PSB (34); PSB (34); PTB (25); DEM (22); PRB (21); PDT (17); SD (15); PSC (12); PROS (11); PC do B (10); PPS (10); PV (8); PHS (5); PSOL (5); PTN (4); PMN (4); PRP (3); PEN (2); PSDC (2); PTC (2); PRTB (1); PSL (1); PT do B (1).

As crenças dos legisladores serão definidas pelas posições ideológicas dos legisladores ${ }^{7}$, de maneira condensada, em esquerda e direita. Adotaremos a distinção ideológica desenvolvida por Scheefer (2018), na qual é considerado o comportamento efetivo dos partidos em votações no Congresso em temasclássicos (intervenção econômica, criminalidade, carga tributária, legislação trabalhista, serviços públicos) e em temas novos (aborto, liberação da maconha, união de pessoas do mesmo sexo, ações afirmativas, questões ambientes, questões morais). Quanto maior o número na escala geral, mais a direita está o partido político. O período de referência é 2011-2015.

Quadro 1 - Escala Ideológica de Partidos em Votações em Plenário na Câmara dos Deputados (2011-15)

\begin{tabular}{c|c}
\hline Partidos & Escala Geral \\
\hline PSOL & 4,1 \\
\hline PT & 26,7 \\
\hline PC do B & 29,4 \\
\hline PDT & 32,4 \\
\hline PPS & 33,4 \\
\hline PV & 38,5 \\
\hline PSB & 41,7 \\
\hline PROS & 48,2 \\
\hline PR & 55,7 \\
\hline PRB & 57,3 \\
\hline PSC & 61,1 \\
\hline PTB & 61,6 \\
\hline
\end{tabular}

\footnotetext{
${ }^{7}$ É consenso dentro das tentativas de estabelecer classificações ideológicas dos partidos no Congresso (BOLOGNESI, BABIRESKI, MACIEL, 2019; SCHEFFER, 2016; TAROUCO, MADEIRA, 2015), que é tarefa difícil ter clareza de definição pelo multipartidarismo e a volatilidade do sistema partidário.
} 


\begin{tabular}{c|c}
\hline PSDB & 62,9 \\
\hline PMDB & 63 \\
\hline DEM & 63,8 \\
\hline PP & 65,4 \\
\hline PSD & 65,7 \\
\hline SD & 68,5 \\
\hline
\end{tabular}

Fonte: Scheeffer (2018)

A definição utilizada neste artigo para grupo de interesse é ampla: inclui não apenas corporações, indústrias e lobistas contratados; mas também "instituições governamentais, como cidades e governos estrangeiros; instituições públicas e privadas como hospitais e universidades, fundações, e organizações filantrópicas; e tantas outras entidades que às vezes se comportam como lobistas ou se tornam de alguma forma ativas em assuntos de interesse público" (BAUMGARTNER, 1999:28).

Para esta análise, agrupamos os grupos de interesse do seguinte modo:

1) Empresariado, agregando empresas, associações comerciais, sindicatos patronais

2) Associações Profissionais e Sindicatos de trabalhadores

3) Estado (Executivo, Judiciário, Legislativo, Ministério Público)

4) ONGs e Movimentos Sociais

5) Especialistas de think tanks, de universidades ou individuais

Sobre estes grupos e suas distinções, podemos indicar algumas particularidades e contribuições prévias sobre suas atuações, afim de elucidar suas distinções. Os grupos representantes de interesses empresariais seriam mais profissionalizados (SANTOS et al, 2017), mais influentes e sui generis, pois tendem a se associar menos com outros e têm ação mais pontual. O lobby da indústria é um bom exemplo de sofisticação e efetividade (MANCUSO; SANTOS, 2004), sendo, portanto, mais efetivos (CESARIO, 2016).

Diferentes trabalhos ${ }^{8}$ confirmam o que seria uma espécie de senso comum: grupos empresariais acabam por ter certas vantagens e são mais bem sucedidos. Existem, contudo, condicionantes, tais como o contex to político de um Congresso favorável e a falta ou a existência de grupos opositores de outros objetivos (HOJNACKI, 2015). A literatura mostra justamente que grupos empresariais são melhor sucedidos quando não encontram tal oposição. Existem, ainda, outras condicionantes contextuais informacionais que podem ser consideradas (VICTOR, 2007).

Os sindicatos e as associações profissionais também possuem suas particularidades, inclusive no Brasil. Os sindicatos, marcados pelo varguismo, possuíam uma forma específica de

\footnotetext{
${ }^{8}$ Para citar apenas alguns clássicos: Schattschneider (1960); Olson (1965) e Lindblom (1975). Gilens; Page (2014) definiram esta corrente de teorias como "Biased Pluralism". Eles buscam responder a pergunta "quem governa na democracia americana?" A resposta é que são grupos de interesse, mas com clara vantagem em grupos de interesses empresariais.
} 
atuação corporativista, mas, a partir dos anos 1970, passaram a ter características mais pluralistas (BALBI, 2012). Na Constituição de 1988, foram previstos aspectos do corporativismo e do pluralismo, formando assim um sistema híbrido. A respeito da atuação em audiências públicas e seminários do Congresso Nacional, há uma centralidade de uniões sindicais com outros grupos do gênero na articulação (CESARIO, 2016).

Há diferenças entre sindicatos e associações profissionais. Uniões sindicais tendem a ter mais membros e possuíram mais relevância na sua individualidade, enquanto associações profissionais atendem a grupos profissionais - ou ocupacionais - mais específicos, podendo até ser divididos por gênero, etnia e orientação sexual (SCHLOZMAN, 2010). Porém, por ser tratarem de grupos que defendem classes em específico, ficou determinado que para os fins deste estudo, que seriam considerados conjuntamente.

Por Estado, se entende todo e qualquer representante de alguma instituição pública pertencente a qualquer um dos três Poderes (Executivo, Legislativo e Judiciário), além do Ministério Público. Incluem-se aí, portanto, Ministros de Estado, membros de autarquias, deputados, senadores, juízes, procuradores, dentre outros. Como se mostra evidente em Figueiredo (2020), representantes estatais são invariavelmente chamados às audiências para discutir os seus temas.

ONGs e movimentos sociais se assemelham ao não possuir fins lucrativos e ao defender bens coletivos. Embora o IBGE aponte que estas entidades crescem ano a ano, Santos (2014) mostra que se comparando 1983 e 1984, o período do início da redemocratização, com 2011 e 2012, nãohouve aumento do número dessas entidades atuando noCongresso Nacional ${ }^{9}$. Isso pode indicar a dificuldade de financiamento da prática do lobby, que requer expressivos recursos.

Por fim, temos os especialistas strictu sensu. Num sentido mais amplo, todo representante de um grupo de interesse que vá ao encontro de um legislador para interferir na sua decisão é um especialista.Porém, se restringirmos, para fins de análise, ficando com aqueles representantes que tenham como atividade-fim a obtenção de saber técnico e especializado, ficaremos com especialistas individuais, ou pertencentes a centros de pesquisa, universidades ou think tanks.

A primeira hipótese a ser testada será: "as preferências ideológicas determinam as preferências de convite dos legisladores a determinadas categorias de grupos de interesse". Esta hipótese provém da concepção de dois tipos de lobby, a partir das crenças dos legisladores: um para reforço de crenças e outros para mudança de crenças (WRIGHT, 1996). A tese mais comum é a do lobby para reforço de crenças, a partir da aproximação de grupos de interesse e legisladores as mesmas preferências (HOJNACKI; KIMBALL, 1998; HALL; DEARDOFF, 2006;

\footnotetext{
${ }^{9}$ O levantamento das Fasfil (Fundações Privadas sem Fins Lucrativos) usado pelo autor como referência, considerando a séries histórica a partir do ano de 2010, incluindo também 2013 e 2016, registra, na verdade, uma queda no número das unidades locais das fundações privadas e associações sem fins lucrativos (https://www.ibge.gov.br/estatisticas/economicas/outras-estatisticas-economicas/9023-as-fundacoes-privad as-eassociacoes-sem-fins-lucrativos-no-brasil.html?edicao $=24159 \& \mathrm{t}=$ series-historicas).
} 
FIGUEIREDO; RICHTER, 2014; GROLL;PRUMMER, 2016; SCHNAKENBERG, 2016). Para o teste, perfis de comportamento de legisladores de esquerda e direita serão buscados, levando em conta a proporção de iniciativas por audiência e de convite a categoria de grupo de interesse. Após isto, as posições ideológicas e suas preferências de convites por determinados grupos de interesse serão consideradas. Por último, será feita a distribuição partido a partido e comissão por comissão.

A segunda das hipóteses a serem testada será: "as audiências públicas são montadas sem contestação de outros parlamentares". Esta hipótese surge da concepção prévia à Teoria Informacional do Legislativo, em que as audiências públicas seriam terrenos inférteis ao debate sério, e seriam um espaço de confirmação das teses defendidas pela Comissão que a convoca (FARNSWORTH, 1961; BAUER ET AL, 1972; DENZAU; MANGER, 1986). O teste dessa hipótese pode trazer luz quanto ao próprio caráter informacional das audiências, e também uma elucidação para dúvida se grupos de interesse buscam legisladores para reforço ou mudança de crenças. Para o teste desta hipótese, o foco estará nos requerimentos feitos por legisladores para o convite de novos participantes, focando no aspecto da "contestação". Caso um partido de ideologia contrária tenha feito um convite que se some ao anterior para a constituição da audiência, a audiência será definida como "contestada". A análise será feita em geral e comissão por comissão.

E finalmente, a terceira hipótese é: "frente ao cargo estratégico do Presidente da Comissão, sua posição ideológica afeta a aprovação de requerimentos de partidos a favor de suas preferências”. Esta hipótese surge do papel formal dos Presidentes das Comissões em aprovação de requerimentos, corroborado pelo poder de agenda que eles possuem (A GUIAR, 2013); além da evidência retirada de Troiano (2017), de que a atuação de grupos empresariais se associa a posições-chaves (relatoria, presidência da comissão e requerente) serem ocupadas por legisladores de direita. Esta hipótese será testada observando as posições ideológicas dos partidos dos presidentes de Comissões em geral e buscar identificar se há efeito na definição dos convidados para as Comissões.

\section{Ideologia no Acesso a Audiências}

A partir de levantamentos descritivos de certas relações de proporções direita e esquerda no total de legisladores na Câmara em comparação às iniciativas feitas por audiências públicas, o traçamento de perfis de comportamento nos convites por grupos de interesse e distinções mais detalhadas partido a partido e comissão a comissão, é possível elucidar o peso das inclinações políticas dos legisladores no acesso de grupos de interesse a audiências públicas nas comissões.

Tomando como referência a escala ideológica de Scheeffer (2018), há uma desproporção de

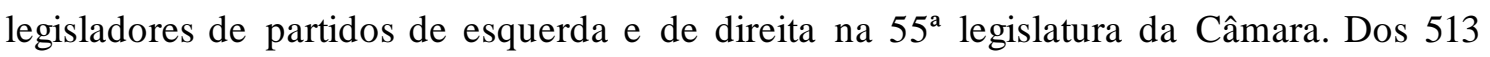
legisladores federais, 323 podem ser considerados de direita, 167 de esquerda e o restante não 
pôde ser classificado. Nesta visãogeral, a proporção(direita/esquerda) é aproximadamente 1,934. Logo, praticamente existem 2 (dois) legisladores de direita para 1 (um) de esquerda. Entretando, na proporção entre os legisladores responsáveis pelo primeiro requerimento de convite para audiências públicas, há maior equilíbrio: das 205 audiências, foram 111 por iniciativa de legislador de direita, 84 de esquerda e o restante (10), não foram classificados; então, uma proporção (direita-esquerda) de 1,321, revelando uma condição de maior igualdade relativa em comparação à proporção geral do Congresso Nacional (Quadro 2).

Quadro 2 - Legisladores na Câmara e legisladores com iniciativa de audiência pública

\begin{tabular}{|l|c|c|c|}
\hline & \multirow{2}{*}{ Direita } & \multirow{2}{*}{ Esquerda } & Proporção \\
\cline { 4 - 5 } & & & (Direita/Esquerda) \\
\hline Legisladores na Câmara & 323 & 167 & 1,934 \\
\hline Iniciativas de Audiência Públicas & 111 & 84 & 1,321 \\
\hline
\end{tabular}

Fonte: elaboração própria, 2020.

Ao estabelecer um "perfil de comportamento" relativos de legisladores de esquerda e direita, é possível concluir que legisladores de esquerda são mais propensos a tomarem iniciativas de audiência públicas que tratam de mudança legislativa do que legislad ores de direita. Cada legislador de direita teve, em média, 0,344 iniciativa, enquanto cada legislador de esquerda teve, em média, 0,503 (Quadro 3) Em termos de proporcionalidade, nas audiências públicas realizadas com vistas a mudanças legislativas, a iniciativa de proposição de audiências e convites se equilibram (111 a 84) mais do que se espera, sendo a Câmara um espaço desproporcional ideologicamente.

Quadro 3 - Média de inicia tivas por legislador de uma posição ideológica

\begin{tabular}{l|c|c|c}
\hline \multicolumn{1}{c|}{ de } & Direita & Esquerda & Total \\
\hline $\begin{array}{l}\text { Número } \\
\text { legisladores }\end{array}$ & 323 & 167 & 490 \\
\hline Número de iniciativas & 111 & 84 & 195 \\
\hline $\begin{array}{l}\text { Média de iniciativas } \\
\text { por legislador }\end{array}$ & 0,344 & 0,503 & 0,398 \\
\hline
\end{tabular}

Fonte: elaboração própria, 2020.

Destes levantamentos expostos nos quadros acima, podemos detectar um "'efeito equalizador" das audiências públicas na Câmara. Por mais que tenham sido eleitos mais legisladores de direita do que de esquerda, no âmbito das audiências, isto não se nota tão claramente no agregado de iniciativas. Uma possível explicação é a escolha estratégica dos próprios grupos de interesse e dos legisladores que se associam a uma visão ideológica a 
participarem ou não de audiências públicas, por enxergarem nelas possibilida de ou não de real influência. Como demonstra Baird (2016), o processo de influência pode ser feito em muitas etapas e a audiência pública pode ser apenas uma das táticas utilizadas para o alcance do objetivo final de influenciar uma decisão. ${ }^{10}$ Somado a isto, diante do "efeito equalizador" detectado, as audiências podem ser vistascomouma tática de influência interessante para minorias ideológicas, que encontrarão espaço de fala nestes espaços, afinal, regimentalmente, as audiências se guiam por princípios de igualdade, contraditório e pluralidade. ${ }^{11}$

Foram feitos 1157 convites por legisladores a grupos de interesse, divididos em cinco diferentes categorias. O levantamento abaixo mostra que partidos de direita fazem $64 \%$ dos convites a grupos do Empresariado, enquanto partidos de esquerda, 34\%. A respeito dos legisladores de esquerda, podemos dizer que têm maior predileção por ONGs e Movimentos Sociais (54\%). Há equilíbrio nos outros grupos: em requerimentos para representantes de associações profissionais e sindicatos de trabalhadores, há 49,6\% para a esquerda e 48,5\% para a direita; para o Estado, 47,3\% para a esquerda e $51 \%$ para a direita; e por fim, na convocação de especialistas, temos $47,7 \%$ pela a esquerda e $51,4 \%$ pela direita. (Quadro 4 ).

É de se destacar a presença relevante de diversos tipos de grupos de interesse: Empresariado (196), Associações Profissionais e Sindicatos (257), Estado (403), ONGs e Movimentos Sociais (170) e Especialistas (110). Sobretudo, por serem da sociedade civil, não apenas de representantes do Estado. A título de comparação, quando audiências foram estudadas por Zorzal (2007), no estado do Espírito Santo, a autora averiguou uma presença muitíssimo maior de participantes governamentais, ligados à máquina pública, e ínfimo de representantes da sociedade civil, no que Romão (2011) denota de ' maior participação da sociedade política em relação à civil’", comum a muitas instituições participativas. É possível dizer que, no caso das audiências da Câmara, há uma representatividade plural da sociedade civil.

Quadro 4 - Convites a grupos de interesse, por posição ideológica

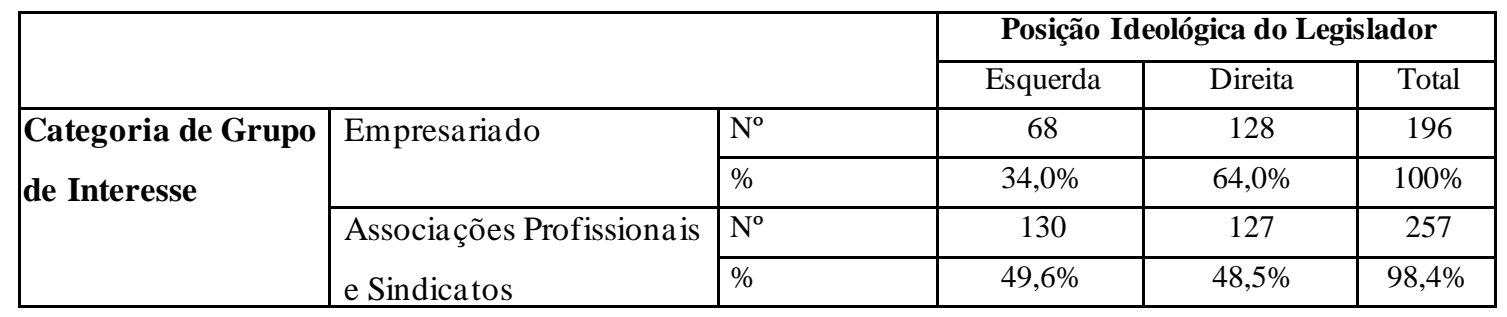

\footnotetext{
${ }^{10}$ Santos et al (2017) aponta uma série de outras táticas possíveis a ser utilizadas no Legislativo: contato direto com os parlamentares, acompanhamento de reuniões das comissões, contatos com a assessoria das comissões, visitas aos gabinetes dos parlamentares, contato com outros grupos para ações articuladas, acompanhamento de reuniões plenárias, contato com líderes, acompanhamento de bancadas e frente e contatos com a consultoria legislativa.

${ }^{11}$ É importante salientar que as audiências públicas surgem na esteira da emergência de mecanismos participativos dentro da sociedade brasileira (AVRITZER; SANTOS, 2002), e estes seguem certos ideais aspiracionais: igualdade, respeito mútuo, ausência de poder coercitivo, uso da razão, busca do consenso e dar clareza aos conflitos, orientação ao bem comum, publicidade, accountability e sinceridade (BATCHINGER et al, 2018).
} 


\begin{tabular}{|l|l|l|c|c|c|}
\hline \multirow{3}{*}{$\begin{array}{l}\text { Categoria de Grupo Interesse } \\
\text { Estado }\end{array}$} & $\mathrm{N}^{\mathbf{0}}$ & 194 & 209 & 403 \\
\cline { 2 - 6 } & $\%$ & $47,3 \%$ & $51,0 \%$ & $98,3 \%$ \\
\cline { 2 - 6 } & $\begin{array}{l}\text { ONGs e movimentos } \\
\text { sociais }\end{array}$ & $\mathrm{N}^{\mathbf{0}}$ & 94 & 76 & 170 \\
\cline { 2 - 6 } & Especialistas & $\mathrm{N}^{\mathbf{0}}$ & $54,0 \%$ & $43,7 \%$ & $97,7 \%$ \\
\cline { 3 - 6 } & $\mathbf{\%}$ & $47,7 \%$ & $57,4 \%$ & $99,1 \%$ \\
\hline
\end{tabular}

Fonte: elaboração própria, 2020.

Novamente, se buscarmos um 'perfil"' no comportamento dos legisladores de esquerda e direita, teremos a relação proporcional apresentada no Quadro 8. Desta relação podemos concluir que, a exceção da forte inclinação de um legislador de direita convidar representantes do Empresariado, nas outras categorias existe equilíbrio entre legisladores de esquerda e direita. (Quadro 5).

Quadro 5 - Proporção direita/esquerda em convites a categoria de grupo de interesse

\begin{tabular}{|c|c|}
\hline Grupo de Interesse & Proporção D/E \\
\hline Empresariado & 1,882 \\
\hline Associação Profissional/ Sindicatos & 0,976 \\
\hline Estado & 0,941 \\
\hline ONGs e Movimentos Sociais & 0,787 \\
\hline Especia listas & 1,075 \\
\hline
\end{tabular}

Fonte: elaboração própria, 2020.

Portanto, é possível concluir que existe de fato uma predisposição maior de legisladores de esquerda a requererem audiências públicas, e além disso, há preferências deconvites por certas categorias de grupos de interesse, principalmente por ONGs e Movimentos Sociais. Por outro lado, legislador de direita, nos dois levantamentos feitos logo acima, se mostram mais inclinados ao convite de grupos ligados ao Empresariado. Esta diferença de comportamento entre os legisladores das duas posições ideológicas, confirmam ainda mais a hipótese de que posições ideológicas explicam os convites por certos grupos de interesse.

Para elevar o nível de detalhe da análise, foi avaliado o comportamento dos partidos políticos individualmente em relação aos requerimentos. (Quadro 6). Caso ignorarmos, as preferências por organizações de Estado, por seu conteúdo 'neutro', pela presença praticamente invariável em audiências públicas ${ }^{12}$, podemos identificar que a escolha preferencial (+) ou maior rejeição (-) de partidos de esquerda ou esquerda podem possuir coerências e também contradições.

\footnotetext{
${ }^{12}$ Como se nota no Quadro 6, a exceção do PSC, que não convidou nenhum representando do Estado, todos os outros partidos convidaram no mínimo em 26,4\% (DEM) representantes do Estado.
} 
Quadro 6 - Convites a categorias de grupos de interesse, por partido

\begin{tabular}{|c|c|c|c|c|c|c|c|}
\hline & \multicolumn{5}{|c|}{ Categorias de Grupo de Interesse } \\
\hline & & & Empresariais & Assoc. & Estado & Ongs e & Especialistas \\
\hline \multirow{42}{*}{$\begin{array}{l}\text { Partido do } \\
\text { Requerente }\end{array}$} & \multirow[t]{2}{*}{ PSOL } & $\mathrm{N}^{\circ}$ & 3 & 3 & 10 & 13 & 3 \\
\hline & & $\%$ & $9,4 \%(-)$ & $9,4 \%(-)$ & $31,3 \%$ & $40,6 \%(+)$ & $9,4 \%(-)$ \\
\hline & \multirow[t]{2}{*}{ PT } & $\mathrm{N}^{\circ}$ & 14 & 35 & 62 & 27 & 25 \\
\hline & & $\%$ & $8,6 \%(-)$ & $21,5 \%(+)$ & $38,0 \%$ & $16,6 \%$ & $15,3 \%$ \\
\hline & \multirow[t]{2}{*}{ PCdoB } & $\mathrm{N}^{\circ}$ & 0 & 6 & 8 & 3 & 1 \\
\hline & & $\%$ & $0,0 \%(-)$ & $33,3 \%(+)$ & $44,4 \%$ & $16,7 \%$ & $5,6 \%$ \\
\hline & \multirow[t]{2}{*}{ PDT } & $\mathrm{N}^{\circ}$ & 13 & 47 & 36 & 17 & 9 \\
\hline & & $\%$ & $10,7 \%$ & $38,5 \%(+)$ & $29,5 \%$ & $13,9 \%$ & $7,4 \%(-)$ \\
\hline & \multirow[t]{2}{*}{ PPS } & $\mathrm{N}^{\circ}$ & 0 & 2 & 4 & 2 & 1 \\
\hline & & $\%$ & $0,0 \%(-)$ & $22,2 \%(+)$ & $44,4 \%$ & $22,2 \%(+)$ & $11,1 \%$ \\
\hline & \multirow[t]{2}{*}{ PV } & $\mathrm{N}^{\circ}$ & 17 & 3 & 14 & 5 & 9 \\
\hline & & $\%$ & $35,4 \%(+)$ & $6,3 \%(-)$ & $29,2 \%$ & $10,4 \%$ & $18,8 \%$ \\
\hline & \multirow[t]{2}{*}{ PSB } & $\mathrm{N}^{\circ}$ & 18 & 17 & 45 & 20 & 5 \\
\hline & & $\%$ & $17,1 \%$ & $16,2 \%$ & $42,9 \%$ & $19,0 \%(+)$ & $4,8 \%(-)$ \\
\hline & \multirow[t]{2}{*}{ PROS } & $\mathrm{N}^{\circ}$ & 3 & 17 & 15 & 7 & 0 \\
\hline & & $\%$ & $7,1 \%$ & $40,5 \%(+)$ & $35,7 \%$ & $16,7 \%$ & $0,0 \%(-)$ \\
\hline & \multirow[t]{2}{*}{ PR } & $\mathrm{N}^{\circ}$ & 10 & 13 & 16 & 2 & 2 \\
\hline & & $\%$ & $23,3 \%$ & $30,2 \%(+)$ & $37,2 \%$ & $4,7 \%(-)$ & $4,7 \%(-)$ \\
\hline & \multirow[t]{2}{*}{ PRB } & $\mathrm{N}^{\circ}$ & 6 & 7 & 17 & 4 & 4 \\
\hline & & $\%$ & $15,8 \%$ & $18,4 \%(+)$ & $44,7 \%$ & $10,5 \%(-)$ & $10,5 \%(-)$ \\
\hline & \multirow[t]{2}{*}{ PSC } & $\mathrm{N}^{\circ}$ & 7 & 2 & 0 & 1 & 1 \\
\hline & & $\%$ & $63,6 \%(+)$ & $18,2 \%$ & $0,0 \%$ & $9,1 \%(-)$ & $9,1 \%(-)$ \\
\hline & \multirow[t]{2}{*}{ PTB } & $\mathrm{N}^{\circ}$ & 1 & 10 & 9 & 4 & 4 \\
\hline & & $\%$ & $3,6 \%(-)$ & $35,7 \%(+)$ & $32,1 \%$ & $14,3 \%$ & $14,3 \%$ \\
\hline & \multirow[t]{2}{*}{ PSDB } & $\mathrm{N}^{\circ}$ & 32 & 30 & 59 & 10 & 18 \\
\hline & & $\%$ & $21,5 \%(+)$ & $20,1 \%$ & $39,6 \%$ & $6,7 \%(-)$ & $12,1 \%$ \\
\hline & \multirow[t]{2}{*}{ PMDB } & $\mathrm{N}^{\circ}$ & 19 & 7 & 31 & 15 & 6 \\
\hline & & $\%$ & $24,4 \%(+)$ & $9,0 \%$ & $39,7 \%$ & $19,2 \%$ & $7,7 \%(-)$ \\
\hline & \multirow[t]{2}{*}{ DEM } & $\mathrm{N}^{\circ}$ & 7 & 25 & 24 & 27 & 8 \\
\hline & & $\%$ & $7,7 \%(-)$ & $27,5 \%$ & $26,4 \%$ & $29,7 \%(+)$ & $8,8 \%$ \\
\hline & \multirow[t]{2}{*}{$\mathrm{PP}$} & $\mathrm{N}^{\circ}$ & 20 & 10 & 15 & 1 & 7 \\
\hline & & $\%$ & $37,7 \%(+)$ & $18,9 \%$ & $28,3 \%$ & $1,9 \%(-)$ & $13,2 \%$ \\
\hline & \multirow[t]{2}{*}{ PSD } & $\mathrm{N}^{\circ}$ & 12 & 4 & 23 & 7 & 5 \\
\hline & & $\%$ & $23,5 \%(+)$ & $7,8 \%$ & $45,1 \%$ & $13,7 \%$ & $9,8 \%$ \\
\hline & \multirow[t]{2}{*}{ SD } & $\mathrm{N}^{\circ}$ & 14 & 19 & 15 & 5 & 2 \\
\hline & & $\%$ & $25,5 \%$ & $34,5 \%(+)$ & $27,3 \%$ & $9,1 \%$ & $3,6 \%(-)$ \\
\hline & \multirow[t]{2}{*}{ PHS } & $\mathrm{N}^{\circ}$ & 1 & 1 & 2 & 2 & 0 \\
\hline & & $\%$ & $16,7 \%$ & $16,7 \%$ & $33,3 \%$ & $33,3 \%(+)$ & $0,0 \%(-)$ \\
\hline & \multirow[t]{2}{*}{ PMN } & $\mathrm{N}^{\circ}$ & 2 & 0 & 3 & 2 & 1 \\
\hline & & $\%$ & $25,0 \%(+)$ & $0,0 \%(-)$ & $37,5 \%$ & $25,0 \%(+)$ & $12,5 \%$ \\
\hline & \multirow[t]{2}{*}{ PTdoB } & $\mathrm{N}^{\circ}$ & 1 & 4 & 2 & 0 & 0 \\
\hline & & $\%$ & $14,3 \%$ & $57,1 \%(+)$ & $28,6 \%$ & $0,0 \%(-)$ & $0,0 \%(-)$ \\
\hline
\end{tabular}


Sob a perspectiva da escolha preferencial, em geral, partidos de esquerda convidam mais entre as categorias Associações Profissionais e Sindicatos (PT, PC do B, PDT, PPS, PROS) e ONGs e Movimentos Sociais (PSOL, PSB). A contradição entre partidos desta posição ideológica está na preferência do PV por convidar entre o empresariado. Entre partidos de direita, é mais comum que convidem grupos empresariais (PSC, PSDB, PMDB, PP, PSD), porém os partidos próximos do corte entre esquerda e direita da escala ideológica, PR e PRB, e os partidos trabalhistas (PTB e SD), preferem convidar associações profissionais ou sindicatos. $\mathrm{O}$ comportamento mais incomum é do DEM, que tem preferência acentuada por ONGs e Movimentos, muito próxima de Associações Profissionais e Sindicatos. Uma explicação possível é que, segundo Scheefer (2018), o partido mudou sua inclinação: da posição de principal partido de direita, para um partido mais próximo do centro.

Pela perspectiva da maior rejeição, complementar à da escolha preferencial, podemos enxergar entre os partidos de esquerda maior rejeição em convidar grupos empresariais (PSOL, PT, PC do B, PPS), também podendo-se destacara rejeição entre especialistas (PSOL, PDT, PSB, PROS). As grandes contradições se dão, novamente, pelo PV, e também pelo PSOL, que não convidam muito entre Associações Profissionais e Sindicatos. Esta rejeição do PSOL pode ser explicada pela inclinação radical do partido a favor de ONGs e Movimentos Sociais. Já os legisladores de partidos de direita, tendem a não convidar muito entre ONGs e Movimentos Sociais (PR, PRB, PSC, PSDB, PP, PSD), assim como Especialistas (PR, PRB, PSC, PMDB, $\mathrm{SD})$. DEM e PTB tendem a não chamar tantos representantes de interesses empresarias. Mais uma vez revelando um comportamento aparentemente contraditório do DEM.

De maneira geral, portanto, existe uma confirmação da tese de aproximação de grupos de interesse e legisladores com as mesmas preferências (HOJNACKI; KIMBALL, 1998; HALL; DEARDOFF, 2006; FIGUEIREDO; RICHTER，2014; GROLL; PRUMMER，2016; SCHNAKENBERG, 2016) ${ }^{13}$, em detrimento de uma aproximação de opostos para uma tentativa de influência, ainda que existam comportamentos aparentemente contraditórios por parte do PV, DEM e PSOL, sem considerar, é claro, um exame maiscuidadoso de outras importantes variáveis, como os programas partidárias e o teor das audiências aos quais os partidos fizeram os convites.

$\mathrm{O}$ artifício de requerer audiências públicas, porém apresenta maior inflexão à direita, quando analisamos detalhadamente comissão por comissão ${ }^{14}$. Ao consideramos as dez comissões com maior número de audiências com vistas mudanças legislativas ocorridas, é mais comum que a maior parte dos requerimentos partam de legisladores de direita no interior das comissões

\footnotetext{
13 As coerências entre partidos e grupos de interesse convidados também podem ser investigados como uma "replicação do jogo partidário na esfera participativa" (COELHO; FAVARETO, 2008), onde partidos acabam por dar ênfase a grupos mais bem relacionados, em detrimentos de outros desfavorecidos em organizações e ligações políticas . ${ }^{14}$ As comissões consideradas foram as que mais tiveram mais audiências públicas que tratam de mudança legislativa no período 2015 a 2015: CSSF (26), CDEICS (25), CCJC (24), CEDU (18), CTASP (17), CAPADR (14), CVT (13), CFT (11). CCTCI (10), CDU (10), CSPCCO (8).
} 
(Quadro 7).

Quadro 7 - Posição ideológica do requerente, por comissão

\begin{tabular}{|c|c|c|c|c|}
\hline Comissão & Esquerda & Direita & Não-Classificado & $\begin{array}{c}\text { Proporção Direita- } \\
\text { Esquerda }\end{array}$ \\
\hline CAPADR & 6 & 8 & 0 & 1,334 \\
\hline CCTCI & 7 & 2 & 2 & 0,286 \\
\hline CCJC & 10 & 12 & 0 & 1,200 \\
\hline CDU & 3 & 7 & 0 & 2,334 \\
\hline CDEICS & 11 & 14 & 0 & 1,273 \\
\hline CEDU & 7 & 11 & 0 & 1,571 \\
\hline CFT & 5 & 6 & 0 & 1,200 \\
\hline CSPCCO & 4 & 4 & 5 & 1,1 \\
\hline CSSF & 10 & 11 & 0 & 1,334 \\
\hline CAPADR & 6 & 8 & 1 & \\
\hline
\end{tabular}

Fonte: elaboração própria, 2020.

É importante pontuar que estes dados por comissão devem ser relativizados por considerarem uma amostra bem menor de audiências que os dados em agregado, porém é interessante notar, além da citada superioridade relativa de requerimentos partindode legisladores de direita em praticamente todas as comissões, a exceção da CCTCI e a CSPCCO, também as diferenças mais expressivas: a CCTCI, como a única comissão dominada por iniciativas por audiências partindo da esquerda, e da CDU, da CTASP e da CVT, proporcionalmente muito mais dominadas pela direita. Estes dados nos dão pistas sobre as preferências de legisladores outrossim, grupos de interesse - sobre suas escolhas estratégicas, em que comissões atuar para conquistar seus interesses, porém de maneira inconclusiva.

\section{Contestação de Audiências Públicas}

Os legisladores possuem viés nos seus convites para audiências públicas. Quando idealizam através do seu primeiro requerimento o tema ali abordado e os convidados que buscam ter presentes, há inclinação às suas preferências. Por isto, é interessante analisar a reação da oposição perante este fato. Outro conceito que surge então é o de "contestação", em contraposição à ideia de que audiências seriam apenas um espaço de confirmação das teses defendidas pela Comissão que a convoca (FARNSWORTH, 1961; BAUER ET AL, 1972; DENZAU \& MANGER, 1986) e do lobby como um subsídio informacional às decisões dos legisladores, sem necessariamente interferir numa mudança de posição mais drástica (HALL; DEARDOFF, 2006).

Estabelecemos duas categorias para as audiências: "contestadas", ou "não-contestadas". A primeira diz respeito àquelas onde outro requerimento é proposto partindo de um legislador 
que é ideologicamente oposto do legislador proponente. Isso indicaria ao menos a intenção de se fazer uma oposição de ideias durante a audiência idealizada por um parlamentar de ideologia diferente. A segunda categoria diz respeito às audiências que prosseguem sem um requerimento apresentado por um legislador de partido ideologicamente oposto do proponente. Então, nesta situação é grande a possibilidade da audiência pública acontecer sem um contraste claro de posições dos convidados.

O levantamento identificou que das 205 audiências, 16,1\% apresentam contestação, ou seja, requerimentos propondo outros convidados para além daqueles previstos pelo requerente. Por outro lado, $80,5 \%$ das audiências mantêm os convidados do primeiro requerimento apresentado pelo legislador requerente (Quadro 8).

Quadro 8 - Audiências públicas contestadas, ou não, ou não-classificadas

\begin{tabular}{|l|c|c|}
\hline & $\mathbf{N}^{\mathbf{0}}$ & \% \\
\hline Contestadas & 165 & 16,1 \\
\hline Não-contestadas & 33 & 80,5 \\
\hline Não classificado & 7 & 3,4 \\
\hline Total & 205 & 100,0 \\
\hline
\end{tabular}

Fonte: elaboração própria, 2020.

As audiências possuem predominância de seu espectro ideológico na sua concepção através do requerimento. Disto, podemos concluir que existe um domínio na sua orientação no que diz respeito a tema e convidados, e uma pré-condição para reforço de um viés. Não significando, contudo, que o domínio dos resultados de influência ocorra ${ }^{15}$. Há outras táticas de lobby possíveis que podem ser utilizadas. Além disso, a divergência e o confronto às opiniões dos convidados não se dão somente por outros convidados, mas também por legisladores durante os debates ${ }^{16}$. Dessa forma, outra dimensão de contestação é a presença plural de legisladores às audiências e o uso que fazem do seu tempo de fala.

Outra informação relevante que pode ser apresentada a partir dos dados são as Comissões com audiências por mudanças na legislação mais “contestadas” ou "não-contestadas" (Quadro 9).

\footnotetext{
15 Vale lembrar que uma estratégia de lobby pode englobar uma série de outras ações (BAIRD, 2016; SANTOS et al, 2017), além da já complicada dificuldade de se mensurar os seus resultados (BAUMGARTNER, 1999), no caso das audiências públicas, é ainda maior. Pois audiências públicas possuem caráter consultivo e nenhum efeito vinculativo a nenhuma decisão diretamente.

${ }^{16}$ É uma prerrogativa regimental a interpelação pelos deputados, trazendo questões ou adendos às falas dos convidados.
} 
Quadro 9 - Contestações de requerimento, por comissão

\begin{tabular}{|c|c|c|c|c|}
\hline & Não-Contestada & & & Índice de Contestação \\
\hline CAPADR & 12 & 2 & 0 & 0,167 \\
\hline CCTCI & 8 & 2 & 1 & 0,25 \\
\hline CCJC & 14 & 9 & 0 & $\mathbf{0 , 6 0}$ \\
\hline CDU & 8 & 2 & 1 & 0,25 \\
\hline CDEICS & 22 & 2 & 0 & 0,087 \\
\hline CEDU & 16 & 2 & 0 & 0,125 \\
\hline CFT & 8 & 3 & 0 & $\mathbf{0 , 3 7 5}$ \\
\hline CSPCCO & 5 & 2 & 2 & $\mathbf{0 , 4 0}$ \\
\hline CSSF & 21 & 3 & 0 & 0,130 \\
\hline CTASP & 16 & 1 & 0 & 0,063 \\
\hline CVT & 11 & 2 & 0,182 \\
\hline
\end{tabular}

Fonte: elaboração própria, 2020.

Ao se estabelecer um índice das audiências "contestadas" divididas pelas "nãocontestadas", podemos ter uma visão mais clara de quais Comissões costumam ter audiências mais contestadas. Novamente, foram consideradas as Comissões com mais audiências que tratam de mudança legislativa que a média. Ficaram como não classificadas as audiências contestadas por partidos não classificados na escala ideológica; ou que teve iniciativas de legisladores desses partidos e, a posteriori, contestada.

Existem, por tanto, três Comissões que se destacam pelo índice maior de contestação. As duas Comissões, $\operatorname{CCJC}(0,6)$ e CFT $(0,375)$, têm em comum que todos os projetos de mudança legislativa devem passar por elas e o caráter terminativo. Por estes motivos, es sas Comissões de "neutralidade temática" acabam por ser um especial alvo de estratégias de influência dos mais variados grupos de interesse e por receber alta participação de parlamentares de esquerda e de direita. As suas Comissões são, portanto, espaços estratégicos e disputados, onde a presença de convidados ligados a diferentes posições ideológicas estarão presentes de forma mais marcante. A CSPCCO $(0,4)$, que trata de temas de segurança pública e crime organizado, teve papel destacado no período de 2015 a 2018, principalmente após a mudança de abordagem na política de segurança pública, a partir do Governo Michel Temer. Junto a esta mudança, vieram debates acalorados em audiências.

Podemos apontar os dados acima como mais uma evidência de que existe um movimento de "reforço de crenças" nas audiências, pois se os grupos de interesse, outrossim os legisladores de uma determinada posição ideológica, nãobuscam interferir numa audiência pública de posição ideológica contrária, não há um esforço para 'mudança de crença'. Este comportamento 'contestador" acaba por se mostrar presente nas comissões tematicamente 'neutras", ou como um evento esporádico. Vieira (2009) já havia identificado, na CDU, uma dinâmica análoga, em que grupos com pontos de vista diferentes evitavam participar numa "efetiva deliberação" numa audiência em específico, preferindo usar de seu espaço para se direcionar aos tomadores de 
decisão sem receber confrontação. A ausência de deliberação também é consistente com as descobertas de Macedo (2018):

\begin{abstract}
(...) as audiências não teriam um caráter deliberativo no sentido das trocas informacionais a respeito de projetos de lei ou outros tipos de propostas. A análise de projetos consome apenas $20 \%$ das audiências. (...) as audiências estão mais concentradas na fiscalização do Executivo e na exploração de assuntos novos (em 2013) (...) (MACEDO, 2018, p.120).
\end{abstract}

Como uma ponderação às conclusões a respeito da dinâmica contestatória analisada, duas outras linhas de raciocínio podem ser tomadas. A primeira é: para além da interpretação da "contestação" proposta nesta análise, existe tambéma possibilidade, embora menos provável, dos requerimentos iniciais terem sido feitos de maneira equilibrada ${ }^{17}$, respeitando as diferentes visões e grupos, não havendo necessidade de um novo requerimento, o que levaria a um debate sobre a força das regras regimentais como efetivadora de princípios deliberativos ${ }^{18} \mathrm{~A}$ segundaé: os atores parte do processo de lobby podem reconhecer audiências públicas enquanto táticas de influência de baixa efetividade dentro de uma estratégia maior de influência e, assim sendo, não dispendem seus recursos tentando mudar crenças de legisladores já inclinados em uma direção. Como se sabe, os recursos dispendidos no lobby são altos (MANCUSO; GOZETTO, 2011) e, especialmente grupos ligados ao Empresariado, são bastante profissionalizados (Santos et al, 2017), levando com que as ações sejam tomadas com cálculo de efetividade, e como se sabe, a mudança posicial frente a tema é caso raro entre tomadores de decisão.

\title{
6 Influência do Presidente da Comissão sobre os Requerimentos por Audiência
}

O Presidente da Comissão é uma posição-chave. Segundo Aguiar (2013), ele é responsável por controle da agenda das reuniões ordinárias, retirar de pauta ex officio proposições, designa relatores contrários e conduz a votação da proposição. Troaino (2017) ap ontou uma dinâmica de aproximação entre grupos doempresariadoe partidos de direita para alcançarsucesso na sua prática de influência sobre projetos. Cabe apontar que uma vez em pauta, a votação da comissão a favor da comissão ocorre apenas pro forma, porém segundo Macedo (2018), há proximidade entre a Presidência da Comissão e o partido do deputado requerente, e comumente, são rejeitados requerimentos de audiência sobre denúncias mais fortes contra o Governo.

No que diz respeito às posições ideológicas, há uma predominância de Presidentes de Comissão de direita nas audiências pesquisadas, refletindo a maioria dos partidos de direita naquela Legislatura. As Comissões foram presididas em $81 \%$ por legisladores de direita, enquanto $17,6 \%$, de esquerda (Quadro 10). Dado o equilíbrio absoluto entre os requerimentos aceitos por

\footnotetext{
${ }^{17}$ É um pressuposto regimental, expresso no $\$ 1$ do art. 256: "Na hipótese de haver defensores e opositores relativamente à matéria objeto de exame, a Comissão procederá de forma que possibilite a audiência das diversas correntes de opinião".
} 
legisladores de esquerda e de direita, é possível afirmar que a posição ideológica de um Presidente de Comissão não afeta o equilíbrio das audiências.

Quadro 10 - Posição ideológica do Presidente da Comissão da audiência

\begin{tabular}{|l|c|c|}
\hline Posição Ideológica do Presidente da Comissão & $\mathbf{N}^{\mathbf{0}}$ & \% \\
\hline Esquerda & 36 & 17,6 \\
\hline Direita & 166 & 81,0 \\
\hline Não classificáveis & 3 & 1,5 \\
\hline Total & 205 & 100,0 \\
\hline
\end{tabular}

Fonte: elaboração própria, 2020.

Existem algumas possibilidades para explicar esse aspecto de indiferença de quem preside a Comissão em incorporar audiências numa 'agenda ideológica'. Uma explicação seria o baixo interesse do Presidente em se indispor politicamente por um mecanismo de lobby e transferência de informação de baixa efetividade. Outra seria o simples interesse maior da esquerda, em relação à direita, em utilizar a audiência pública para direcionar seus posicionamentos aos legisladores. Como foi averiguado pelos dados sobre iniciativas por audiências, existe um 'efeito equalizador' provocado pelas audiências, além do arcabouço regimental propício à pluralidade e a igualdade, que favorece as minorias, portanto, para a esquerda e seus grupos de interesse mais próximos, a audiência pode representar uma oportunidade estratégica de trazer à luz seus pontos de vista e criar uma compensação de sua desvantagem numérica em eleitos na Câmara.

\section{Conclusão}

Deste artigo, que pretendeu averiguar a importância das crenças ideológicas dos legisladores como uma determinante do acesso de grupos de interesse a audiências públicas da Câmara dos Deputados, foi possível, a partir da exposição descritiva de dados, detectar padrões de comportamento nos convites de legisladores de esquerda e de direita, revelar detalhes sobre a dinâmicas de 'contestação' em proposições por novas audiências públicas e dirimir a importância do Presidente da Comissão como um definidor de uma agenda ideológica.

As premissas teóricas de que existe uma aproximação de "'iguais", no que diz respeito a ideologias de grupos de interesse e legisladores (MCKAY, 2008; 2010) e com o intuito de promover um reforço de crenças (HOJNACKI; KIMBALL, 1998; HALL; DEARDOFF, 2006; FIGUEIREDO; RICHTER, 2014; GROLL; PRUMMER, 2016; SCHNAKENBERG, 2016), foram confirmadas com ressalvas atra vés da análise dos requerimentos. Existe aproximação maior entre legisladores de esquerda com ONGs e Movimentos Sociais, assim como, de legisladores de direita com o Empresariado. Por outro lado, existe igualdade de requerimentos nas outras categorias consideradas. As contradições notáveis estão na análise partido a partido, que mostram 
o DEM possuindo comportamento típico de um partido de esquerda, enquanto PV possui forte aproximação com o Empresariado e o PSOL, que evita convidar Associações Profissionais e Sindicatos.

A 'contestação' dos requerimentos iniciais de audiências públicas foi demonstrada como uma dinâmica incomum, com exceção de três comissões: a CCJC, a CFT e a CSPCCO. Havendo um maior destaque às duas primeiras, pois são comissões terminativas, ou seja, de importância diferenciada das demais e um caráter "neutro", por todos os projetos passarem por elas independente de qualquer decisão política.

Por último, foi concluído que a agenda deaudiências públicas das comissõesnãoé afetada pela posição ideológica do Presidente da Comissão, que mesmo sendo em grande maioria de direita (81\%), não existe uma inclinação maior para a aceitação de audiências de esquerda. Muito pelo contrário, é mais uma confirmação de um 'efeito equalizador"' das audiências públicas, sob o aspecto ideológico.

Uma conclusão geral, confirmada por todas as hipóteses traz luz às escolhas estratégicas escolhidas pelos diferentes grupos em disputa. Sabemos que os grupos do Empresariado, mais ligados à Direita, possuem uma série de vantagens competitivas sobre os outros, possuindo maior ef etividade nas suas estratégias (MANCUSO, 2004; TAGLIAGNA, 2006; MANCUSO, 2011; SANTOS, 2015; SANTOS ET AL, 2017; CESÁRIO, 2016; TROIANO, 2017). Portanto, a audiência pública pode ser vista, por seus princípios de igualdade, transparência e contraditório, como uma tática usada por grupos minoritários e com menos recursos como uma forma de encontrar espaço de fala para atingir influência. Ao passo, que grupos e legisladores ligados ao Empresariado não usem de todo o seu potencial numérico para fazer uso destes espaços, talvez preferindo outras táticas de influência mais efetivas e menos transparentes.

Algumas questões elucidadas por este trabalho, no entanto, carecem de exame mais cuidadoso. Devido ao estudo empírico manter o foco sobre o requerimento e o acesso, outras dinâmicas de uma audiência acabam por não serem analisadas, como a presença ou não de convidados, a atuação dos deputados e representantes de grupos de interesse nas audiências em si e o alcance os efeitos almejados pelo lobby ou não. Estas análises seriam melhor feitas estudando casos individuais, não em agregado, como foi o objetivo deste artigo.

\section{Bibliografia}

AVRITZER, Leonardo; SANTOS, Boaventura de Sousa. Para ampliar o cânone democrático. Democratizar a democracia: os caminhos da democracia participativa. Rio de Janeiro: Civilização Brasileira, p. 39-82, 2002.

AGUIAR, Osmar de Oliveira. Os Atores-chave no processo decisório no âmbito das comissões permanentes. E-Legis, v. 6, n. 12, p. 137-152, 2003.

AUSTEN-SMITH, David; Wright, John. Competitive Lobbying For a Legislator's Vote. Social Choice And Welfare, v. 9, n. 3, p. 229-257, 1992. 
BÄCHTIGER, André et al. Deliberative Democracy. The Oxford handbook of deliberative democracy. Oxford University Press, 2018.

BACOVIS, Maria Cristina; SANTOS, Fabiano. Alarme de Incêndio como Estratégia Legislativa: O Caso da Comissão de Direitos Humanos e Minorias da Câmara dos Deputados. E-Legis, v. 12, n.30, p. 72-88, 2019.

BAIRD, Marcello Fragano. O lobby na regulação da publicidade de alimentos da Agência Nacional de Vigilância Sanitária. Revista de Sociologia e Política, v. 24, n. 57, p. 67-91, 2016.

BALBI, Irineu Belo. Entre o corporativismo e o pluralismo: um estudo sobre o sistema de representação de interesses dos trabalhadores. Revista Habitus, v. 10, n. 1, p.123-137, 2012.

BAUER, Raymond; POOL, Ithiel De Sola; DEXTER, Lewis Anthony. American Business \& Public Policy. The International Executive, v. 5, n. 3, p. 25-27, 1963.

BAUMGARTNER, Frank r.; Leech, Beth 1. Basic Interests: The Importance Of Groups In Politics And In Political Science. New Jersey: Princeton University Press, 1998.

BARROS, Antonio Teixeira de; MONTEIRO, Adriana Resende and SANTOS, Thais Teixeira. Audiências públicas interativas na Câmara dos Deputados: além da função informacional. Revista Brasileira de Ciência Política, n.26, p.131-185, 2018.

BOLOGNESI, Bruno; BABIRESKI, Flávia Roberta; MACIEL, Ana Paula. Conhecendo o vazio: congruência ideológica e partidos políticos no Brasil. Política \& Sociedade, v. 18, n. 42, p. 86-116, 2019.

BRELÀZ, Gabriela de; ALVES, Mário Aquino. O processo de institucionalização da participação na Câmara Municipalde São Paulo: uma análise das audiências públicas do orçamento (1990 -2010). Revista de Administração Pública, v. 47, n. 4, p. 803-826, 2013.

CESÁRIO, Paulo Silva. Redes de influência no Congresso Nacional: Como se articulam os principais grupos de interesse. Revista de Sociologia e Política, n. 24, p. 109-127, 2016.

DAHM, Matthias; PORTEIRO, Nicolas. Informational lobbying under the shadow of political pressure. Social Choice and Welfare, v. 30, n. 4, p. 531-559, 2008.

DENZAU, Arthur T.; MUNGER, Michael C. Legislators And Interest Groups: How Unorganized Interests Get Represented. American Political Science Review, v. 80, n. 4, p. 89-106, 1986.

FARNSWORTH, David Nelson. The Senate Committee On Foreign Relations. Urbana: University of Illinois Press, 1961.

FIGUEIREDO, John M. de; RICHTER, Brian Kelleher. Advancing the empirical research on lobbying. Annual Review of Political Science, v. 17, n. 3., p. 163-185, 2014.

FREITAS, Andréa Marcondes De. O Presidencialismo Da Coalizão. Tese De Doutorado. Universidade de São Paulo. Programa de Pós-Graduação em Ciência Política, 2013.

GILENS, Martin; PAGE, Benjamin I. Testing theories of American politics: Elites, interest groups, and average citizens. Perspectives on Politics, v. 12, n. 3, p. 564-581, 2014.

GROLL, Thomas; PRUMMER, Anja. Whom to lobby? targeting in political networks. Working Paper Series, School of Economics and Finance, Queen Mary University of London, 2016.

HANSEN, John Mark. Gaining Access: Congress and the farm lobby, 1919-1981. Chicago: University Of Chicago Press, 1991.

KASNIUNAS, Nina Therese. Impact Of Interest Group Testimony On Lawmaking In Congress. University Chicago Press, 2009.

KREHBIEL, Keith. Information and legislative organization. University of Michigan Press, 1992.

HALL, Richard L.; Deardorff, Alan V. Lobbying As Legislative Subsidy. American Political Science Review, v. 100, p. 69-84, 2006. 
HOJNACKI, Marie; KIMBALL, David C. Organized Interests And The Decision Of Whom To lobby In Congress. American Political Science Review, v. 92, n. 3., p. 775-790, 1998.

LEYDEN, Kevin M. Interest Group Resources And Testimony At Congressional Hearings. Legislative Studies Quarterly, v. 57, n.3, p. 431-439, 1995.

MACEDO, Silvia Mugnatto. Deliberação e barganha nas audiências públicas das Comissões Permanentes da Câmara dos Deputados. Tese de Doutorado. Universidade do Estado do Rio de Janeiro. Programa de Pós-Graduação em Sociologia e Ciência Política, 2018.

MANCUSO, Wagner Pralon. O lobby Da Indústria No Congresso Nacional: Empresariado e Política No Brasil Contemporâneo. Dados, v. 47, n. 2, p. 505-547, 2004.

MANCUSO, Wagner Pralon; Gozetto, Ana Cristina Oliveira. 2011. Lobby: Instrumento Democrático De Representação De Interesses? Organicom, v. 8, n.2., p. 118-128, 2011.

MCKAY, Amy. A simple way of estimating interest group ideology. Public Choice, v. 136, n. 1-2, p. 69-86, 2008.

MCKAY, Amy. The effects of interest groups' ideology on their PAC and lobbying expenditures. Business and Politics, v. 12, n. 2, p. 1-21, 2010.

RESENDE, Ciro Antônio Da Silva. Representação de Interesses na Câmara Dos Deputados: Estratégias, Atores e Agenda Política. Revista Brasileira De Ciência Política, n.23, p. 123-139, 2017.

ROMÃO, Wagner de Melo. Conselheiros do Orçamento Participativo nas Franjas da Sociedade Política. Lua Nova, n. 84, p. 219-244, 2011.

SANTOS, Fabiano; Almeida, Acir. Teoria Informacional e a Seleção De Relatores Na Câmara Dos Deputados. Dados, v. 48, n. 2, p. 693-735, 2005.

SANTOS, Fabiano. O Legislativo em busca de informação: Um Estudo Da Estrutura De Assessoria Da Câmara Dos Deputados. Texto para Discussão IPEA. Brasília, Instituto de Pesquisa econômica Aplicada, n. 1958, p. 23-41, 2014.

SANTOS, Manoel Leonardo. Representação de interesses na arena legislativa: os grupos de pressão na Câmara Dos Deputados (1983-2012). Texto para Discussão IPEA. Brasília, Instituto de Pesquisa econômica Aplicada, n. 1975, p. 35-48, 2014.

SANTOS, Manoel Leonardo. Financiamento de Campanha e Apoio Parlamentar à Agenda Legislativa da Indústria na Câmara Dos Deputados. Opinião Pública, v. 21, n. 1, p.33-59, 2015.

SANTOS, Manoel Leonardo. Lobbying no Brasil: Profissionalização, Estratégias e Influência. Texto para Discussão IPEA. Brasília, Instituto de Pesquisa econômica Aplicada, n. 2334, p.1734, 2017.

SCHEEFFER, Fernando. A Alocação Dos Partidos No Espectro Ideológico a Partir Da Atuação Parlamentar. E-Legis. v. 11, n. 28, p. 119-142, 2018.

SCHLOZMAN, Kay Lehman. Counting the voices in the heavenly chorus: Pressure Participants In Washington Politics. London: Palgrave Macmillan, 2002.

SCHNAKENBERG, Keith E. Informational lobbying and legislative voting. American Journal of Political Science, v. 61, n. 1, p. 129-145, 2017.

TAGLIALEGNA, Gustavo H; CARVALHO, Paulo Afonso. Atuação de grupos de pressão na tramitação do Projeto De Lei De Biossegurança. Revista De Informação Legislativa, v. 43, n.169, p. 161-188, 2006.

TAROUCO, Gabriela da Silva; MADEIRA, Rafael Machado. Os partidos brasileiros segundo seus estudiosos: análise de um expert survey. Civitas, v. 15, n. 1, p. 24-39, 2015.

TROIANO, Mariele. Os Empresários no Congresso Nacional: a Legitimação de Interesses via Audiências Públicas. Tese de Doutorado. Programa de Pós-Graduação em Ciência Política. 
Universidade Federal de São Carlos, 2017.

WRIGHT, John R. Interest Groups and Congress: Lobbying, Contributions, and Influence. Boston: Allyn \& Bacon, 1996.

VIEIRA, Ricardo Modesto. O estudo do lobby no legislativo: caso de sucesso da Comissão de Desenvolvimento Urbano da Câmara dos Deputados. E-Legis, v.1, n. 2, p. 45-59, 2009.

ZAMPIERI, Enio. Ação dos Grupos de Pressão No Processo Decisório das Comissões Permanentes do Congresso Nacional. E-Legis, v. 12, n. 26, p. 122-136, 2013.

ZORZAL, Gabriela; CARLOS, Euzeneia. Audiências públicas do Legislativo estadual: fatores endógenos e exógenosna análise daefetividade da participação. Revista de Sociologia e Política, v. 25, n. 64 , p. $23-46,2017$.

Artigo recebido em: 2020-08-06

Artigo reapresentado em: 2020-09-28

Artigo aceito em: 2020-09-28 